\title{
Quanto vale ou é por quilo? 0 peso da publicação acadêmica na área de ensino
}

\section{Giselle Rôças}

giselle.rocas@ifri.edu.br

orcid.org/0000-0002-1669-7725

Instituto Federal do Rio de Janeiro,

Rio de Janeiro, Brasil

Maylta Brandão dos Anjos

maylta.anjos@ifri.edu.br

Instituto Federal do Rio de Janeiro,

Rio de Janeiro, Brasil

Marcus Vinicius Pereira

marcus.pereira@ifri.edu.br

orcid.org/0000-0002-8203-7805

Instituto Federal do Rio de Janeiro

Rio de Janeiro, Brasil

\section{RESUMO}

O artigo se volta para a análise da produtividade na área acadêmica, em particular na área de Ensino, a qual está voltada, sobretudo, para a compreensão das ações da Educação Básica, com um público composto basicamente por professores, que estão repensando as práticas profissionais. Busca-se entender o estado da arte do tema, a partir da análise das posições acerca do processo da avaliação, que se faz dos cursos de pós-graduação pelo quantitativo de publicações. Acena-se para algumas ações que se iniciam em um repensar dos processos de avaliações sofridos até agora, sobretudo, no que se relaciona ao peso da publicação na área de ensino, e sugerem-se novas formas de ponderação, que têm no barema um ponto fulcral de discussão. Dentro desse campo, há que se caminhar pelos estudos dos últimos indicadores, que podem se estender à análise da qualidade dos artigos publicados. Há que também estabelecer aproximações entre os programas de pósgraduação no escopo e proposição para estabelecimento de qualidade na pesquisa, que considere o tempo de reflexão e experimentação de forma adequada.

PALAVRAS-CHAVE: Produção acadêmica. Ensino. Processo de avaliação. Pós-graduação. 


\section{INTRODUÇÃO}

Uma carreira acadêmica em que a pessoa é forçada a produzir textos científicos em grande quantidade gera o risco da superficialidade intelectual. $^{1}$

Quanto vale um docente? Este profissional é avaliado pela produção acadêmica, pelo envolvimento com a extensão ou ainda pela capacidade de formar recursos humanos de qualidade? São questões como essas que levaram a alusão ao filme "Quanto vale ou é por quilo?", lançado em 2005, dirigido por Sérgio Bianchi, que trata de uma analogia entre o período da escravidão e a sociedade contemporânea, sendo estabelecido um paralelo entre aquela escravidão de séculos passados e a "escravidão" numérica perseguida pelos docentes de cursos de pós-graduação stricto sensu.

Neste artigo, aborda-se uma indagação constante, principalmente, em ano de avaliação quadrienal (antes trienal) da Coordenação de Aperfeiçoamento de Pessoal de Nível Superior (CAPES), no que tange ao peso e à necessidade da quantificação das publicações, dando recorte à área de Ensino. Sabe-se que, cada vez mais, o monitoramento do desempenho docente, por meio de sistemas de avaliação e baremas específicos se tornou um mecanismo de "qualidade" educacional, medida de produção e configuração de produtividade. Os indicadores de desempenho acirram os ânimos e aumentam disputas e competitividades no meio acadêmico, trazendo para esse cenário uma corrida por publicação, por criação de revistas, por produção técnica, publicação de livros, entre tantas outras ações, que muitas vezes ocorrem em detrimento de fatos, que mantêm a ordem da qualidade das pesquisas, dos projetos, dos experimentos, das análises realizadas. Percebe-se, hoje, a era do "citar sem ler", ou ainda, "da citação que se busca no Google e encaixa no texto", sem a devida leitura crítica do texto completo.

A escolha pela área 46 de Ensino da CAPES se deve ao fato dos autores serem docentes de um Programa de Pós-graduação stricto sensu (PPG) recomendado por essa área, sendo, portanto, mais conhecedores dessa realidade. Entretanto, as outras 47 áreas possuem baremas e indicadores, que são tão ou mais numéricos / restritivos do que os da área de Ensino, estando todos disponíveis nos respectivos documentos de área e nas páginas da internet das avaliações trienais anteriores da CAPES.

A área de Ensino é a segunda maior área da CAPES, concentrando, atualmente, 177 cursos de pós-graduação recomendados, sendo 68 Mestrados Acadêmicos (MA), 76 Mestrados Profissionais (MP) e 33 Doutorados Acadêmicos (DA), em praticamente todos os Estados do Brasil (exceto Amapá e Piauí), embora haja uma grande concentração nas regiões Sul e Sudeste. A área está voltada para um público composto, especialmente, por professores, os quais buscam a formação continuada com o objetivo de repensarem a prática profissional, forrando-a com o estofo do recorte teórico, sem tirarem os seus "pés do chão da escola". É na vivência desses sujeitos que a experiência se transforma em pesquisa. O contrário não a inviabiliza, mas há que se aprofundar essa discussão na área, buscando meios para que artigos não se convertam para suprir demandas métricas, que definirão somente abertura e manutenção de cursos, mas que estas sejam tratadas dentro das possibilidades de se repensar a qualidade do ensino, retroalimentado pela pesquisa. 
Em 2011, a então denominada área de Ensino de Ciências e Matemática teve seu escopo ampliado, recebendo PPG de ensino de diferentes áreas do conhecimento, passando a se chamar apenas Ensino. Entretanto, há que se ter uma conversa entre os saberes específicos das distintas áreas e os saberes pedagógicos necessários para a formação de um profissional titulado como mestre ou doutor em ensino, sendo sempre pensada a formação do profissional, que trabalhará na Educação Básica, no Ensino Superior e/ou em espaços não formais. Assim, observa-se uma crescente aproximação da área das Ciências da Saúde, Ciências Humanas e Sociais e alguns ensaios das engenharias.

As 48 áreas de avaliação da CAPES são regidas por diretrizes propostas e discutidas pelos coordenadores dos PPG, que compõem cada área, os quais comparecem aos Seminários de Acompanhamento realizados pela CAPES ao menos uma vez por ano. Durante essa imersão de dois a três dias são discutidos a produção da área e novos rumos e esses momentos de interação entre coordenadores de programa e a coordenação da área é vital para o entendimento das necessidades, reconhecimento dos avanços e retrocessos, mas, principalmente, para o estabelecimento de normativas e grupos de trabalhos, que geram material para a construção dos documentos, que orientam a avaliação quadrienal e, por conseguinte, as ações e metas dos PPG. Entretanto, os coordenadores e as comissões de avaliação não são as únicas vozes presentes nos documentos de área, uma vez que cada documento é encaminhado para um relator de uma área distinta, além de ser avaliado pelo Comitê Técnico Científico (CTC) da CAPES, sofrendo modificações por aqueles que não acompanham as discussões práticas e epistemológicas intrínsecas à área. Trata-se, portanto, de um documento polifônico e, de certa forma, hibridizado.

Conhecer o documento de área (cada área tem documento e diretrizes próprias) é tarefa primeira e fundamental para aqueles, que pretendem propor um novo curso de mestrado e/ou doutorado, e essencial para os docentes que pretendem atuar e se manter credenciados, a fim de qualificar seus PPG. Conhecer as demandas, exigências, diferenças e expectativas dos avaliadores se torna vital, principalmente, quando uma instituição possui cursos recomendados em uma mesma área, mas de modalidades distintas, a saber: profissional e acadêmica. A compreensão dos objetivos e requisições para cada uma das modalidades de cursos existentes também varia para cada uma das áreas. No caso específico da área Ensino, compreende-se que:

O Mestrado Acadêmico tem foco na formação de recursos humanos com vistas ao fortalecimento da pesquisa em ensino no país e à docência universitária. Visa aprofundar a formação científica e integrar às práticas docentes os saberes disciplinares, pedagógicos e resultados de pesquisa na Área de Ensino. Destina-se a profissionais que atuam em contextos formais ou não formais de ensino, sejam eles professores da educação básica e/ou superior, licenciados, bacharéis e outros (BRASIL, 2016a, p.2, grifo nosso).

Os Mestrados Profissionais da Área de Ensino são diferentes de Mestrados Acadêmicos e não suas variações ou adaptações. [...] Seu foco está na aplicação do conhecimento, ou seja, na pesquisa aplicada e no desenvolvimento de produtos e processos educacionais que sejam implementados em condições reais de ensino. Esta deve ser a ênfase dos Mestrados Profissionais da Área. 
Destinam-se principalmente a professores da educação básica e/ou profissionais de ensino formal ou não formal nos diferentes campos de conhecimento, bem como a profissionais atuantes no ensino em saúde, educação profissional e tecnológica ou qualquer outra temática que caracterize as profissões contemporâneas (BRASIL, 2016a, p.14, grifo nosso).

Outro ponto a ser pensado acerca das diferentes modalidades de mestrado é que, sob a perspectiva do "quanto vale ou é por quilo?", são os MP da área de Ensino os mais analisados e discutidos no âmbito acadêmico - (CEVALLOS; PASSOS, 2012; BRANDÃO; DECACCHE-MAIA; BOMFIM, 2013; MOREIRA, 2004; RÔÇAS et al., 2011; VILELA; BATISTA, 2015; VILLANI, 2016), sendo constantemente contrapostos quanto ao seu escopo e produção, ou seja, finalidade e alcance do que se produz, para além do estudo traduzido em dissertação. Considerando o volume dedicado à compreensão do papel dos MP aliada à ausência (ou baixa) produção de artigos oriundos de pesquisas, que se debrucem sobre os MA e DA, pode-se inferir que tais cursos atendem aos objetivos previstos e que o estranhamento e preconceito, quando da criação dos MP ainda não foi totalmente resolvido. Assim, é preciso que a discussão sobre o papel dos MP destaque a premência de se compreender que, conforme aponta a legislação, não se tratam de variações ou adaptações da modalidade acadêmica, e já é passado da hora de se romper com o pragmatismo e privilégios na formação e construção do saber.

Entender que a existência das duas modalidades de pós-graduação stricto sensu no Brasil é intrinsecamente diferente, mas com finalidades únicas de formação, é ponto que reconduz a análise e publicações para patamares, que correspondam à diretriz e vocação primeira dos cursos. Pautados na compreensão de que ao longo dos 17 anos de existência a área de Ensino já acumula discussão e cursos de qualidade reconhecida, em ambas as modalidades, é que se prossegue com esse artigo, que objetiva iniciar uma discussão sobre a produtividade imputada atualmente aos docentes, que atuam na pós-graduação stricto sensu e, quiçá, estimular a proposição de metodologias distintas de avaliação da produtividade para a avaliação quadrienal de 2021. Para isso, opta-se por uma análise qualitativa de cunho bibliográfico (GIL, 2008), efetuando o levantamento dos documentos que regem os distintos sistemas de avaliação utilizados pela CAPES (BRASIL, 2017). Essa opção por pesquisas que elevem o processo de crítica e autocrítica de quem se mantém e faz pesquisa é considerado um ato essencial e importante para se pensar e repensar o papel de pesquisadores da área de Ensino.

\section{OS DIFERENTES CRITÉRIOS DE AVALIAÇÃO}

Os quesitos previstos nas fichas de avaliação são comuns às 48 áreas da CAPES, tanto para a modalidade profissional quanto acadêmica, diferindo quanto à distribuição da pontuaçã̃o. Cada quesito recebe um conceito (Muito Bom, Bom, Regular, Fraco ou Insuficiente) em cada um dos itens, de acordo com definições estabelecidas pela comissão de avaliadores, a qual é escolhida com base em critérios definidos no regulamento da avaliação quadrienal (BRASIL, 2017). A avaliação é classificatória, evitando concentração de notas nos diferentes níveis 
da escala, e também é comparativa entre as áreas, ainda que guarde especificidades, pois:

[...] pauta-se pelo mesmo conjunto de quesitos e itens avaliativos e deve promover a equivalência de qualidade de desempenho entre programas com as mesmas notas nas distintas áreas de avaliação. Cada nota deve, portanto, corresponder ao mesmo nível de qualidade para todas as áreas de avaliação. Cabe ao CTC-ES a responsabilidade de garantir a equivalência entre as notas atribuídas pelas diferentes Comissões de Áreas de Avaliação (BRASIL, 2017, p.4).

A ficha de avaliação para o quadriênio 2013-2016 possui algumas novidades em relação à utilizada no triênio 2010-2012, além de uma revisão na distribuição dos pesos dos quesitos, o que pode acarretar na pontuação de alguns itens somente para a modalidade acadêmica ou profissional. Como o foco desse estudo, que é a área de Ensino, se apresenta, portanto, os pesos para essa área na Tabela 1 a seguir. É importante destacar que o quesito: Proposta não possui peso algum, quando comparado aos demais quesitos previstos na ficha, embora possua itens com distribuição interna, pois se trata de um quesito de ordem qualitativa, sendo utilizado em situações de nota limítrofe $(2 \leftrightarrow 3 ; 3 \leftrightarrow 4 ; 4 \leftrightarrow 5$; $5 \leftrightarrow 6 ; 6 \leftrightarrow 7)$, podendo diminuir ou aumentar a nota, de acordo com os resultados obtidos na análise dos itens do quesito. Alguns itens são avaliados somente para os cursos da modalidade acadêmica e outros somente para a modalidade profissional. Diante da possibilidade de doutorados profissionais, já se pode antecipar que essa ficha sofrerá modificações em alguns desses itens para que essa modalidade de doutorado não existente seja contemplada.

Tabela 1 - Ficha de avaliação de cursos de mestrado e doutorado (2013-2016).

\begin{tabular}{|c|c|c|}
\hline FICHA DE AVALIAÇÃO & ACADÊMICO & PROFISSIONAL \\
\hline Quesito 1 - PROPOSTA DO PROGRAMA & - & - \\
\hline $\begin{array}{l}\text { 1.1 Coerência, consistência, abrangência e atualização } \\
\text { das áreas de concentração, linhas de pesquisa, projetos } \\
\text { em andamento e proposta curricular / Demandas. }\end{array}$ & $60 \%$ & $50 \%$ \\
\hline $\begin{array}{l}\text { 1.2 Planejamento do programa com vistas a seu } \\
\text { desenvolvimento futuro, contemplando os desafios } \\
\text { internacionais da área na produção do conhecimento, } \\
\text { seus propósitos na melhor formação de seus alunos, } \\
\text { suas metas quanto à inserção social mais rica dos seus } \\
\text { egressos, conforme os parâmetros da área. }\end{array}$ & $30 \%$ & $20 \%$ \\
\hline $\begin{array}{l}1.3 \text { Infraestrutura para ensino, pesquisa e, se for o caso, } \\
\text { extensão. }\end{array}$ & $10 \%$ & $10 \%$ \\
\hline $\begin{array}{l}\text { 1.4 Coerência, consistência e abrangência dos } \\
\text { mecanismos de interação efetiva com outras } \\
\text { instituições, atendendo a demandas sociais, } \\
\text { organizacionais ou profissionais. }\end{array}$ & - & $20 \%$ \\
\hline Quesito 2 - CORPO DOCENTE & $15 \%$ & $15 \%$ \\
\hline $\begin{array}{l}\text { 2.1 Perfil do corpo docente, consideradas titulação, } \\
\text { diversificação na origem de formação, aprimoramento e } \\
\text { experiência, e sua compatibilidade e adequação à } \\
\text { Proposta do Programa. }\end{array}$ & $20 \%$ & $50 \%$ \\
\hline $\begin{array}{l}2.2 \text { Adequação e dedicação dos docentes permanentes } \\
\text { em relação às atividades de pesquisa e de formação do } \\
\text { programa. }\end{array}$ & $35 \%$ & $20 \%$ \\
\hline
\end{tabular}




\begin{tabular}{|c|c|c|}
\hline $\begin{array}{l}2.3 \text { Distribuição das atividades de pesquisa e de } \\
\text { formação entre os docentes do programa. }\end{array}$ & $30 \%$ & $20 \%$ \\
\hline $\begin{array}{l}\text { 2.4 Contribuição dos docentes para atividades de ensino } \\
\text { e/ou de pesquisa na graduação, com atenção tanto à } \\
\text { repercussão que este item pode ter na formação de } \\
\text { futuros ingressantes, quanto na formação de profissionais } \\
\text { mais capacitados no plano da graduação. }\end{array}$ & $15 \%$ & $10 \%$ \\
\hline Quesito 3 - CORPO DISCENTE, TESES E DISSERTAÇÕES & $35 \%$ & $30 \%$ \\
\hline $\begin{array}{l}3.1 \text { Quantidade de teses e dissertações defendidas no } \\
\text { período de avaliação, em relação ao corpo docente } \\
\text { permanente e à dimensão do corpo discente / Números. }\end{array}$ & $30 \%$ & $35 \%$ \\
\hline $\begin{array}{l}\text { 3.2 Distribuição das orientações das teses e dissertações } \\
\text { defendidas no período de avaliação em relação aos } \\
\text { docentes do programa. }\end{array}$ & $10 \%$ & - \\
\hline $\begin{array}{l}\text { 3.3 Qualidade das Teses e Dissertações e da produção } \\
\text { de discentes autores da pós-graduação e da graduação } \\
\text { (no caso de IES com curso de graduação na área) na } \\
\text { produção científica do programa, aferida por } \\
\text { publicações e outros indicadores pertinentes à área / } \\
\text { Aplicabilidade. }\end{array}$ & $40 \%$ & $40 \%$ \\
\hline 3.4 Aplicabilidade dos trabalhos produzidos. & - & $25 \%$ \\
\hline $\begin{array}{l}\text { 3.5 Eficiência do Programa na formação de mestres e } \\
\text { doutores bolsistas: Tempo de formação de mestres e } \\
\text { doutores e percentual de bolsistas titulados. }\end{array}$ & $20 \%$ & - \\
\hline Quesito 4 - PRODUÇÃO INTELECTUAL & $35 \%$ & $30 \%$ \\
\hline $\begin{array}{l}\text { 4.1 Publicações qualificadas do Programa por docente } \\
\text { permanente / Produção Acadêmica. }\end{array}$ & $50 \%$ & $20 \%$ \\
\hline $\begin{array}{l}\text { 4.2 Distribuição de publicações qualificadas em relação } \\
\text { ao corpo docente permanente do Programa. }\end{array}$ & $30 \%$ & $20 \%$ \\
\hline $\begin{array}{l}\text { 4.3 Produção artística, técnica, patentes, inovações e } \\
\text { outras produções consideradas relevantes / Produção } \\
\text { Educacional. }\end{array}$ & $20 \%$ & $40 \%$ \\
\hline $\begin{array}{l}\text { 4.4 Articulação da produção artística, técnica e científica } \\
\text { entre si e com a proposta do programa / Produção \& } \\
\text { Proposta. }\end{array}$ & - & $20 \%$ \\
\hline Quesito 5 - INSERÇÃO SOCIAL & $15 \%$ & $25 \%$ \\
\hline $\begin{array}{l}5.1 \text { Inserção e impacto regional e (ou) nacional do } \\
\text { programa. }\end{array}$ & $45 \%$ & $40 \%$ \\
\hline $\begin{array}{l}5.2 \text { Integração e cooperação com outros programas e } \\
\text { centros de pesquisa e desenvolvimento profissional } \\
\text { relacionados à área de conhecimento do programa, com } \\
\text { vistas ao desenvolvimento da pesquisa e da pós- } \\
\text { graduação }\end{array}$ & $35 \%$ & $20 \%$ \\
\hline $\begin{array}{l}5.3 \text { Visibilidade ou transparência dada pelo Programa à sua } \\
\text { atuação. }\end{array}$ & $20 \%$ & $20 \%$ \\
\hline $\begin{array}{l}5.4 \text { Integração e cooperação com organizações e/ou } \\
\text { instituições setoriais relacionados à área de } \\
\text { conhecimento do Programa, com vistas ao } \\
\text { desenvolvimento de novas soluções, práticas, produtos } \\
\text { ou serviços nos ambientes profissional e/ou acadêmico / } \\
\text { Integração com os serviços e sistemas. }\end{array}$ & - & $20 \%$ \\
\hline
\end{tabular}

Fonte: Adaptado de Brasil (2016b).

Os quesitos Corpo Docente e Produção Intelectual estão diretamente associados à atuação e desempenho dos professores (permanente ou colaborador), mas que também são indiretamente avaliados no quesito 3 , quanto 
que tangenciam a relação de orientação, tais como: quantidade de teses e dissertações defendidas em relação ao corpo docente permanente, distribuição das orientações em relação aos docentes e, especialmente, qualidade das dissertações e teses avaliadas pela conversão dessas em publicações ou aplicações. No quesito 5, Inserção Social, se avalia como ocorrem as relações entre o PPG e seu entorno, considerando aqui as possibilidades de interações com setores públicos e privados, com outros PPG, a visibilidade que possui e a relação entre as ações de extensão com a pesquisa desenvolvida nos cursos. É um quesito que vem ganhando destaque nas últimas avaliações devido ao papel importante de interlocução entre as Instituições de Ensino Superior e pesquisa com os demais setores da sociedade.

$\mathrm{Na}$ área de Ensino se percebe uma evolução na classificação e conceituação das múltiplas formas de produção possíveis, a saber: produção acadêmica (PA), produção técnica (PT) e produção educacional (PE). A pontuação difere entre os tipos de produção e por área e, no Quadro 1 a seguir, indica-se a pontuação vigente para a área de Ensino. Chama-se a atenção para a hierarquização dos artigos científicos sobre as categorias livros e eventos. O livro no melhor estrato de classificação alcança quase a mesma pontuação de um artigo publicado em periódico classificado no estrato B1 para a área, ao passo que o trabalho completo publicado no evento com a melhor classificação alcança pontuação menor que um artigo publicado em periódico classificado no estrato B4. Entretanto, destaca-se ganho considerável com 0 reconhecimento do envolvimento da pesquisa na elaboração dos $\mathrm{PE}$, elementos obrigatórios para um curso de MP, que até então não haviam sido avaliados. Na quadrienal atual, o melhor PE terá a mesma pontuação que um artigo publicado em periódico classificado no estrato $\mathrm{A} 1$ da área de Ensino, o que poderá dar fôlego aos MP, mas também implicará em uma drástica alteração na estratificação da pontuação para alcançar cada nota para as duas modalidades de pós-graduação. 
Quadro 1 - Pontuação conferida a cada um dos estratos dos diferentes tipos de produção intelectual previstas para um programa de pós-graduação stricto sensu da área de Ensino.

\begin{tabular}{|c|c|c|c|c|c|c|c|c|}
\hline \multicolumn{9}{|c|}{ PRODUÇÃO BIBLIOGRÁFICA } \\
\hline \multicolumn{9}{|c|}{ Artigos em periódicos } \\
\hline Estrato & A1 & A2 & B1 & B2 & B3 & B4 & B5 & Obs \\
\hline pontos & 100 & 85 & 70 & 55 & 40 & 25 & 10 & Sem limites \\
\hline \multicolumn{9}{|c|}{ Livros avaliados } \\
\hline Estrato & $\mathrm{L} 1$ & L2 & L3 & L4 & NC & & & Obs: \\
\hline pontos & 10 & 25 & 50 & 75 & 0 & & & Sem limites \\
\hline \multicolumn{9}{|c|}{ Capítulos em livros avaliados } \\
\hline Estrato & C1 & C2 & C3 & C4 & NC & & & Obs: \\
\hline pontos & 5 & 12,5 & 25 & 37,5 & 0 & & & Com limites" \\
\hline \multicolumn{9}{|c|}{ Trabalhos completos em anais de eventos (com mais de 5 páginas e em site aberto) } \\
\hline Estrato & E1 & E2 & E3 & E4 & NC & & & Obs: \\
\hline pontos & 5 & 10 & 15 & 20 & 0 & & & Com limites" \\
\hline \multicolumn{9}{|c|}{ PRODUÇÃO TÉCNICA* } \\
\hline \multicolumn{9}{|c|}{ Produtos educacionais avaliados para Mestrados Profissionais (2017) } \\
\hline Estrato & Edu1 & Edu2 & Edu3 & Edu4 & Edu5 & & & Obs: \\
\hline pontos & 100 & 85 & 60 & 40 & 15 & & & Sem limites \\
\hline \multicolumn{9}{|c|}{ Produtos técnicos-educacionais avaliados para Programas Acadêmicos (2013 e 2017) } \\
\hline Estrato & T1 & $\mathrm{T} 2$ & T3 & & & & & Obs: \\
\hline pontos & 1 & 5 & 10 & & & & & Com limites" \\
\hline
\end{tabular}

* Serviços técnicos não pontuam; \# - máximo 2 capítulos por autor por obra; \#\# máximo de 3 vezes o número de trabalhos completos em anais de eventos relativamente ao número de artigos em periódicos.

Fonte: Documento de Área (BRASIL, 2016b).

Na quadrienal 2013-2016 cada área conferirá pontuações distintas, mas reconhecendo que algumas produções alcançam a mesma pontuação dos artigos publicados em periódicos. Recentemente, a diretora de avaliação da CAPES publicou um artigo falando sobre o Qualis Periódico, e apresentou dez itens sobre esse instrumento de avaliação, incluindo o histórico de sua criação, destacando, entretanto, usos inadequados, tais como:

[...] pelos editores científicos, pelos comitês de assessoramento do CNPq e pelas próprias universidades ou institutos de pesquisa na avaliação de docentes e pesquisadores. O uso da classificação do Qualis pelos editores científicos para obtenção de fomentos e pelas agências para aprová-los é bastante discutível em se tratando da competição entre periódicos dos diferentes campos científicos, na medida em que as classificações são incomensuráveis, como anteriormente demonstrados. As características da classificação com suas regras de proporções pré-fixadas para os estratos superiores, e os diferentes critérios classificatórios usados pelas diferentes áreas, além da possibilidade do recurso à indução ou sobrevalorização de determinados periódicos, tornam seu uso como aferidor da qualidade do periódico, fora do âmbito da avaliação de programas, bastante discutível. (BARATA, 2017, p.36).

\section{O QUE SE ESPERA DE UM CORPO DOCENTE?}


Segundo Maccari (2008), avaliação quantitativa promovida pela CAPES expõe critérios que privilegiam quantificações, em que critérios de qualidades vão se diluindo e, não somente a produção eiva, mas também a própria construção do pensamento trabalhado nos cursos e seus resultados deságuam na produção dos professores. A quantificação da produção, muitas vezes, gera comparações entre os docentes, levando não mais a formação de parcerias, mas a infeliz busca de superação do outro na quantidade, desprezando ações que deveriam se interrelacionar entre ensino, pesquisa e extensão. Em algumas, ou muitas publicações, a dimensão da subjetividade não cabe em uma avaliação pontual e quantitativa. Para Maccari (2008), o sistema de avaliação adotado no Brasil confere maior eficiência sintética, que faz com que se abranja um número de publicações científicas consideráveis, que deve se localizar nos patamares dos países localizados no dito primeiro mundo.

Conforme se visualiza, na ficha de avaliação, para um MP o corpo docente deve ter, além de outras produções, a produção técnica em Ensino; projetos de intervenção e ação em educação; atuação na sala de aula; retorno de pesquisa aos sujeitos que analisa e/ou perfaz as ações profissionais; atuação nas centralidades de formação, nas diferentes modalidades do ensino, desse modo, há também que se voltar para o fortalecimento da formação professores; fortalecimento da popularização e divulgação da ciência; estender planos de criação, inovações e tecnologia, entre outros. Portanto, o foco está na aplicação do conhecimento, na ação profissional, nos resultados aplicados, na evolução dos processos educacionais, que sejam implementados nas escolas e em condições reais de ensino, além da produção acadêmica tão esperada para um docente.

A avaliação das condições de funcionamento dos cursos gera inquietações, indagações, preocupações no estabelecimento de objetivos de produção a todo o custo, mesmo que sejam hostis ao passo da qualidade e vitalidade reflexiva do saber. Tais situações podem conduzir a repensar os interesses, que unem o corpo de um PPG a corresponder aos anseios e características das instituições, no sentido de observar, sobretudo, o peso que a publicação assume atualmente para a CAPES e, em particular, na área de Ensino (vide Quadro 2).

Trazer para o debate um assunto que já ocupa grande parte das discussões no seio acadêmico é colocar luz sobre aquilo que se precisa formular mais profundamente e construir ideias no sentido de modificações. O sistema de avaliação da pós-graduação brasileira é comum a todas as áreas, independente dos escopos dos cursos e, nesse contexto, compreender os pesos dos itens para cada quesito potencializa que cada área possa mudá-los, após os Seminários de Acompanhamento e com a aprovação do CTC, entretanto continua-se a fustigar aos docentes com indicadores cada vez mais difíceis de serem alcançados. As avaliações consideram a evolução das propostas dos PPG desde a sua implementação, mas é no corpo docente; corpo discente; produção intelectual e inserção social que se localizam os principais ícones avaliativos, ficando cada vez mais reforçadas as tendências protocolares do "to publish or perish". Isso ganha luz nas universidades brasileiras, sobretudo, nas últimas décadas, mas é no Parecer no 977 (BRASIL, 1965) de definição dos cursos de pós-graduação stricto sensu, que reside a raiz do que hoje se discute como avaliação acadêmica (SANTOS; AZEVEDO, 2009). De acordo com Cury (2005), nos anos 1960 o escopo das avaliações dos primeiros PPG foi pautado na necessária divulgação das pesquisas, entretanto, como afirma Velloso (2002), antes de 1965 já havia 27 
cursos de mestrado e 11 de doutorado, mesmo sem haver uma definição da estrutura, objetivos ou finalidade da pós-graduação no país.

Kunzer e Moraes (2005), em um histórico sobre a evolução da avaliação dos PPG, destacam que no início dos anos 1990 não era mais possível avaliar com a mesma tônica proposta na década de 1960. O novo modelo de avaliação alterava a centralidade do objeto a ser avaliado: da docência do pesquisador para a pesquisa feita pelo pesquisador. Uma série de outras alterações foi realizada com impactos na compreensão e análise do percurso curricular, das linhas de pesquisa, dos projetos e dos produtos de pesquisa, das teses e de dissertações. Antes, os interesses dos docentes definiam os objetos de investigação, que seriam tomados e perseguidos pelos alunos, agora as linhas de pesquisa do PPG passam a ser o fiel da balança. Entretanto, os pontos negativos oriundos dessas mudanças são sentidos, e ampliados, até os dias atuais.

Por um lado, a exacerbação quantitativista que, como de resto ocorre com os modelos econométricos, só avalia o que pode ser mensurado. [...] No entanto, a qualidade da produção - o verdadeiramente relevante - dificilmente pode ser mensurada, porquanto ainda não se descobriu uma fórmula razoável e rápida para avaliar a qualidade em termos do impacto social e científico dos produtos na qualidade de vida, na democratização social e econômica, na preservação do ambiente e assim por diante. A avaliação qualitativa reclamaria, também, a leitura de artigos e livros, além de teses e dissertações. [...] as exigências relativas à produção acadêmica geraram o seu contrário: um verdadeiro surto produtivista em que o que conta é publicar, não importa qual versão requentada de um produto, ou várias versões maquiadas de um produto novo. A quantidade institui-se em meta. Deste modo, formas legítimas de produção, como coautorias e organizações de coletâneas - em inúmeros casos produtos de sólidas pesquisas integradas -, banalizaram-se no âmbito de algumas áreas de conhecimento, entre elas a Educação. [...] Dessa forma, o incentivo para que orientadores e orientandos publiquem juntos, a partir de uma crescente participação do corpo discente nos projetos de pesquisa dos orientadores desvirtua-se, reduzindo-se a um incansável roteiro de sucessivas apresentações em eventos, no exterior e no país (KUENZER; MORAES, 2005, p.1347-1348).

Da criação da CAPES aos dias atuais, há uma preocupação expressa no sentido da manutenção e desenvolvimento do sistema de pós-graduação, nesse caso já se discutia e objetivava a formação de professores, o fortalecimento da pesquisa, visando ao necessário fortalecimento das universidades brasileiras e a retroalimentação do Ensino Superior (MENDONÇA, 2002). Anísio Teixeira demonstrava preocupação com as pesquisas e com as instituições responsáveis por estas, considerando que tal formação continuava na dependência da atuação aleatória de pequenos grupos de professores, e defendia a necessidade de construir um programa eficiente de estudos pós-graduados (NUNES, 2000). Esse ideal não era exclusivo a Anísio Teixeira, mas a todos que com ele produziram o Parecer no 977 (BRASIL, 1965), assinalando que essa era a condição básica à universidade, que cresce em um caráter universitário, "para que deixe de ser instituição apenas formadora de profissionais e se transforme em centro criador 
O histórico brasileiro da educação e da pós-graduação evidencia a influência recebida pelo funcionamento hierarquizado herdado no regime militar, em uma estrutura fechada e competitiva (FÁVERO, 1989). Essas características se constituíram e somaram aos apelos de um novo status ligado à máxima produtivista, e publicar se torna o principal objetivo e desejo em detrimento do ensino, da extensão e, quiçá, da pesquisa, que passa a ser a maior meta dos pesquisadores de várias universidades e centros de pesquisa do país.

O publish or perish (YAMAMOTO, 2000) que impera como uma das críticas ao modelo empresarial da produtividade é discutido como mote de definição de qualidade, visando a lógica da visibilidade, da competição e do reconhecimento de forma a alimentar um mercado que apresente "o quanto vale ou é por quilo?" da produção acadêmica imputada aos docentes por estes mesmos nos PPG acadêmicos e/ou profissionais. A meta dessa lógica se relaciona, também, com a busca de pertencer ao ingresso na comunidade internacional de pesquisa (MARRARA, 2007).

Tal como ocorre em áreas mais antigas e tradicionais da pesquisa, a área de Ensino não escapa à perpetuação da lógica, que remete à mercantilização dos produtos articulados e escritos e que, muitas vezes, são frutos de pesquisas rápidas e ainda não consolidadas. Paralelamente, descortina-se um mercado de revistas "pagas" em que os autores, com recursos institucionais ou individuais, alçam o pagamento das taxas para serem "mais competitivos" ao terem os nomes associados a um artigo com DOI, com chances mais concretas de sucesso em editais de fomento. Há que se pensar esse propósito dentro de um compêndio maior, para que não se furte da pesquisa e do ensino as vocações primeiras. Apesar de parecer uma "oportunidade" à divulgação e à disseminação da pesquisa, o fato enseja discussões de cunho acadêmico e científico, que remontam à discussão da finalidade ética e transformadora dos resultados das pesquisas, ou seja, o estabelecimento de prioridades que incidam na qualidade e aplicação das pesquisas deve ser resgatado em um cenário, que solicita descobertas, problematizações e inserções para a melhoria do viver. Remete a uma imersão na literatura dos seus pares, evitando fato corriqueiro nos textos atuais ditos acadêmicos como o "citar sem ler", a "citação Lego" buscada no Google para encaixe no texto, ou mesmo a "citação muleta", que revela falta de autoria, corroborada inclusive por orientadores ao assumirem que qualquer ideia, qualquer frase, precisa ser referenciada, em um movimento de apagamento do autor, tornando-o mero compilador de citações.

Ainda que a disponibilização de artigos seja incentivada para que possa ser acessado por todos, a prioridade não deve incidir na mera citação. $O$ tom maior da qualidade da revista, nomeadamente, diante do atual quadro de aumento exponencial de artigos circulando na internet, deve ser a pesquisa em si e a citação do artigo pela pertinência. Nesse caso, na lógica da dinâmica da operosidade, o peso que mais vale é o da difusão do artigo e não o número de acessos e citações. Isso vale mais que os artigos que são mais repetidos e, provavelmente, aceitos no hermético mundo da produtividade (KUHLMANN JR., 2014), o que evitaria escândalos como aqueles provocados pelos periódicos predatórios, mesmo que, segundo Velterop (2016), tenha trazido algo de positivo para a discussão.

Outro ponto a ser pensado é o peso a que se remete a indução da produção acadêmica e sua visibilidade, em tempos de redes sociais, que aceleram e 
catalisam produção de pensamento e pesquisa, bem como a reprodução de ideias já realizadas e, porque não, datadas. O contexto do "publique, apareça ou/e pereça" é real, ele solapa criatividades ameaçando o que se constrói, de mais reflexivo e contundente, da pesquisa. Do mesmo modo, a postura ética que deveria frisar, na produção, na divulgação e no fazer acadêmico fica pulverizada em uma lógica de manter o sentido da hegemonia da visibilidade do currículo Lattes. O pensamento produtivista, que se estabelece nas medidas atuais, que "inventaria" os professores não corrobora com a qualidade da pesquisa, porque no nexo causal atual a produção é feita de forma aligeirada, açodada e superficial, importando prazo e quantidade acima da aplicabilidade, resultado e difusão dos resultados.

Na perspectiva do "quanto vale ou é por quilo?", traduzido no peso da publicação na área de Ensino, analisa-se nos programas de pós-graduação que o principal elemento do sistema de avaliação se compõe do corpo docente, pois os sujeitos integram os quesitos 2, 3 e 4 de forma total ou parcial ao se analisarem os quesitos avaliados. A pesquisa, ao avesso do sentido de publicar ou perecer, acontece de forma mais livre e qualitativa, quando sinaliza a melhoria da produção intelectual, se aporta na experimentação e na formação, na inserção social, na veiculação do conhecimento por sua produção (BIANCHETTI, 2011).

Por fim, é com o corpo docente de um PPG que todas as áreas crescem. Retomando o foco para a área de Ensino, o corpo docente possui especificidades distintas para as modalidades acadêmica e profissional. Conforme preconizado, no documento, sobre os critérios para abertura de novos cursos, para um mestrado acadêmico, por exemplo, espera-se que o corpo docente seja:

[...] qualificado, produtivo e com experiência de orientação. Sua formação e/ou produção devem ser coerentes com o campo de formação/atuação/produção expresso na(s) sua(s) área(s) de concentração e linhas de pesquisa da proposta. O curso deve ter uma base sólida em seu núcleo de professores permanentes, sem depender de professores colaboradores, que devem ser vistos como profissionais que agregam valor à equipe, seja por sua boa capacidade produtiva e de orientação ou por ter a perspectiva de ser docente permanente e se encontrar em trânsito entre outros campos e o do Ensino. A categoria docente colaborador não deve ser vista como um status provisório para docentes não produtivos. [...] Produção docente qualificada com inserção nos estratos A1 a B3, bem distribuída entre os docentes permanentes em periódicos científicos registrados no Qualis periódico da Área. A produção contabilizada na análise da proposta é a referente aos últimos quatro (04) anos, sendo observada a evolução e a experiência do grupo, quando necessário. (BRASIL, 2016a, p.3)

Não se está advogando, contrariamente, a existência de critérios, pois se compreende que a área de Ensino já possui maturidade suficiente e número significativo de doutores formados, devendo ser reforçado em documentos futuros, que as novas propostas tragam uma porcentagem de doutores da área, compreendendo que eles participaram das múltiplas discussões e epistemologias, que vêm sendo consolidadas há muitas décadas. Também se defende que o corpo docente comprove ação conjunta de pesquisa em anos anteriores ao da proposta, para que não seja um "ajuntamento" de docentes, mas um corpo de 
trabalho afinado, com propósitos alinhados, tal qual exigência feita por outras áreas da CAPES. O foco aqui se remete à questão do uso de métricas para cursos, ainda em fase de submissão, uma vez que a lógica do "quanto vale ou é por quilo?" seja aplicada cada vez mais cedo pela CAPES. A métrica a que se refere é baseada no cálculo de pontuação da PA, PT e PE de cada docente, quando a parametria para a área de Ensino na avaliação trienal de 2013 revelou o valor mediano de 120 pontos, em produção, para cada docente de um MP, 500 pontos para MA e 700 pontos para DA para manutenção da nota mínima de aprovação e funcionamento de um curso (BRASIL, 2013). Chama-se a atenção para a composição da pontuação, quando foi avaliada a conjunção da PA e da PT, nesse momento, os PE eram somente computados. Todos os pontos são computados com base na produção dos docentes nos últimos quatro anos (até 2013, três anos), e nos últimos cinco anos, quando da análise de uma proposta de curso novo. A pontuação para o credenciamento / recredenciamento de um docente em um PPG da área de Ensino é calculada de acordo com o Quadro 2.

Quadro 2: Sugestão de roteiro para credenciamento de docente.

\begin{tabular}{|c|c|c|c|}
\hline \multicolumn{4}{|l|}{ Candidato a docente: } \\
\hline CV Lattes: & \multicolumn{3}{|c|}{ Pesquisador do CNPq: ( ) não ( ) sim, nível: } \\
\hline \multicolumn{4}{|c|}{ Vinculo na IES: ( ) 40h ( ) outro, qual: } \\
\hline \multicolumn{4}{|c|}{ Tempo para atuação no PPG: ( ) 20h ( ) outro, qual: } \\
\hline \multicolumn{4}{|c|}{ Linha de pesquisa do PPG que vai reforçar: } \\
\hline \multicolumn{4}{|c|}{ Projeto do PPG em que vai contribuir: } \\
\hline \multicolumn{4}{|l|}{ Disciplina(s) em que vai atuar: } \\
\hline \multicolumn{4}{|c|}{ Número de alunos que pretende orientar no triênio: } \\
\hline Indicadores quantitativos & Pontos & № em 3 anos & Pontos totais \\
\hline Artigos A1 & 100 & & \\
\hline Artigos A2 & 85 & & \\
\hline Artigos B1 & 70 & & \\
\hline Artigos B2 & 55 & & \\
\hline Artigos B3 & 40 & & \\
\hline Artigos B4 & 25 & & \\
\hline Artigos B5 & 10 & & \\
\hline Artigos C & 0 & & \\
\hline \multicolumn{4}{|l|}{ Soma total A1-B1 no triênio } \\
\hline \multicolumn{4}{|l|}{ Soma total A1-B5 no triênio } \\
\hline Livros L1 & 10 & & \\
\hline Livros L2 & 25 & & \\
\hline Livros L3 & 50 & & \\
\hline Livros L4 & 75 & & \\
\hline Capítulos L1 & 5 & & \\
\hline Capítulos L2 & 12,5 & & \\
\hline Capítulos L3 & 25 & & \\
\hline Capítulos L4 & 35,5 & & \\
\hline
\end{tabular}




\begin{tabular}{|c|c|}
\hline Material educativo T1 & 10 \\
\hline Material educativo T2 & 5 \\
\hline $\begin{array}{l}\text { Trabalhos completos em Eventos } \\
\text { E1 }\end{array}$ & 5 \\
\hline Orientação em nível médio & - \\
\hline Orientação em graduação & - \\
\hline Orientação em extensão & - \\
\hline Orientação de lato sensu & - \\
\hline Orientação de mestrado & - \\
\hline Orientação de doutorado & - \\
\hline Supervisão de pós-doutorado & - \\
\hline $\begin{array}{l}\text { Proposta de número de } \\
\text { orientandos/triênio }\end{array}$ & 一 \\
\hline Captação de recursos & - \\
\hline Cooperação com grupo nacional & - \\
\hline $\begin{array}{lll}\text { Cooperação } & \text { com } & \text { grupo } \\
\text { internacional } & & \\
\end{array}$ & - \\
\hline TOTAL DE PONTOS NO TRIÊNIO & - \\
\hline
\end{tabular}

Fonte: Tabela encaminhada no Informativo 9 da área de Ensino em 24 de janeiro de 2014.

Tal qual apontado em momentos anteriores, faz-se necessário que esses critérios estabelecidos sejam gerados a partir da comparação de todos os docentes da área de Ensino. Dessa forma, destaca-se a Tabela 2 abaixo, que foca em alguns elementos importantes (mas não únicos) que um docente precisa atender de acordo com as diferentes notas de um curso.

Tabela 2 - Indicadores centrais de referência para a Área de Ensino com base na avaliação trienal 2013

\begin{tabular}{c|c|c|c|c|c|c}
\hline \multirow{2}{*}{$\begin{array}{c}\text { Indicador para 3 } \\
\text { anos }\end{array}$} & \multicolumn{2}{|c|}{ Programas Acadêmicos } & \multicolumn{3}{c}{ Programas Profissionais } \\
\cline { 2 - 7 } & Nota 3 & Nota 4 & Nota 5 & Nota 3 & Nota 4 & Nota 5 \\
\hline $\begin{array}{c}\text { Pontos totais/DP } \\
\text { Pontos em artigos } \\
\text { A1-B1/DP }\end{array}$ & 150 & 250 & 350 & 60 & 90 & 180 \\
\hline $\begin{array}{c}\text { Pontos em artigos } \\
\text { A1-B5/DP }\end{array}$ & 250 & 350 & 450 & 120 & 200 & 270 \\
\hline $\begin{array}{c}\text { Materiais } \\
\text { Educativos/DP }\end{array}$ & 1 & 2 & 5 & 2 & 4 & 6 \\
\hline $\begin{array}{c}\% \text { mínimo de } \\
\text { Docentes }\end{array}$ & $80 \%$ & $75 \%$ & $70 \&$ & $80 \%$ & $75 \%$ & $70 \%$ \\
\hline \begin{tabular}{c} 
Permanentes (DP) \\
\hline
\end{tabular}
\end{tabular}

Fonte: Relatório de Avaliação 2010-2012 (BRASIL, 2013, p.41-42).

É importante destacar que um grupo multidisciplinar tem perfil que interessa a CAPES e à área de Ensino, entretanto nem todos atendem aos patamares mínimos exigidos, sendo necessário um investimento da instituição para promover esse grupo ao alcance dos indicadores mais importantes, destacados 
acima. Ainda que o perfil multidisciplinar na área de Ensino seja incentivado pela CAPES, este demanda investimentos institucionais, que requerem diferenciada produção científica e tecnológica. A produção científica tem seu esteio nos artigos publicados em periódicos, livros, capítulos, coletâneas em livros e trabalhos completos em eventos seu maior aporte. Enquanto a produção tecnológica tem na elaboração de tecnologias, formação de patentes, desenvolvimento de softwares, execução de protótipos, elaboração de processos, propostas de novas metodologias, realização de consultorias, elaboração de pareceres e relatórios técnico-científicos o seu aporte e maiores produções.

Em decorrência disso, o corpo docente juntamente com os discentes é cada vez mais convocado à produção, o que pode subverter a necessidade de tempo para instituir qualidade às atividades. Dentro dessa ótica, as metas de produção científica e tecnológica caminham no sentido de atender às exigências da avaliação dos PPG. Na esteira dessa avaliação outras demandas surgem, como a necessidade de tradução de artigos para outras línguas, copy-desk, revisão de português, formatação e tratamento estatístico, acesso e domínio de plataformas nas instituições de fomento à pesquisa etc.. Além do ensino, da extensão e da pesquisa que sustentam e fomentam as publicações, a participação em eventos para a troca entre os pares, a formação de novos recursos humanos, a interlocução com os cursos de graduação, entre tantas outras ações e reações, que não são possíveis de serem quantificadas em métricas e números, pois mesmo a vida acadêmica é maior do que o currículo Lattes e a plataforma Sucupira (Figura 1).

Figura 1 - Pichação como forma de protesto a pressão produtivista da área acadêmica.

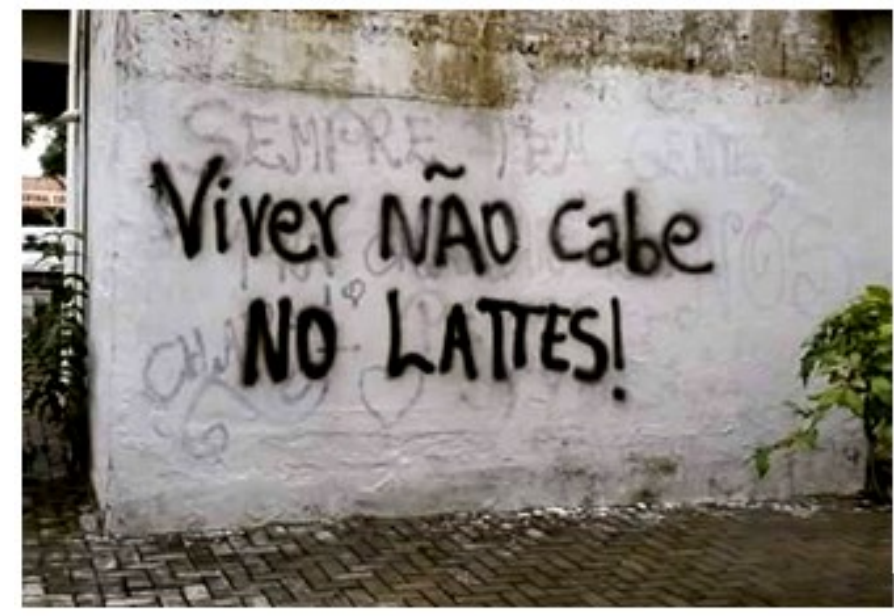

Fonte: Disponível em:<https://www.pinterest.com/pin/124974958386162386/>.

\section{CONSIDERAÇÕES FINAIS}

A partir dos elementos expostos pode-se aludir algumas ações, que se iniciam em um repensar dos processos de avaliação sofridos até agora, sobretudo no que se relaciona ao peso da publicação na área de Ensino. Para isso, sugeremse novas formas de ponderação que têm no barema algumas sinalizações do estabelecimento dessas avaliações que cada vez mais se localizam em um ritmo que ora subverte à máxima dos processos reflexivos, que carecem de tempo de 
apropriação para a pesquisa e para a apuração de seus resultados. Dentro desse campo, há que se caminhar pelos estudos dos últimos indicadores, que podem se estender à análise da qualidade dos artigos publicados para além da ponderação pelo Qualis.

Há que se discutir como as políticas de incentivo e indução para a produção, bem como os programas de inserção social que se configuram na área. Nesse sentido, a inserção social eleva a nota de um curso na avaliação quadrienal, sendo responsável por pelo menos $20 \%$ da nota de um PPG. Entende-se por inserção social para a área de Ensino todo e qualquer impacto (social, educacional, sanitário, tecnológico, econômico, ambiental, cultural, artístico e legal, entre outros, que poderão ser adicionadas pelas várias subáreas do Ensino), que aborde o atendimento obrigatório de uma ou mais dimensões nos níveis local, regional ou nacional. Não se espera que os PPG de todas as áreas e subáreas atendam a todos, pois cada um tem a própria especificidade. Entretanto, a inserção e interação com o respectivo setor externo/social foram consideradas indispensáveis no caso de um MP, por exemplo, e deveriam evidenciar resultados relevantes, objetivamente descritos e apreciados.

A produção de forma global deve ser analisada sob outro prisma. Em vez de se qualificarem os instrumentos de publicação ou de veiculação dos resultados das pesquisas com o intuito de ser quantificada a totalidade da produção dos docentes, se poderia avaliar, de forma mais aprofundada, uma súmula das publicações, conforme já é realizado atualmente pela FAPESP. Os docentes e o PPG seriam convidados a declararem na Plataforma Sucupira aquelas produções pelos quais pretendem ser avaliados. Que se estabeleçam limites mínimos e máximos para a indicação individual ou por PPG ao longo do quadriênio, possibilitando que as comissões se debrucem de forma a realizarem uma avaliação mais qualitativa do que "simplesmente" gerar critérios ou indicadores puramente quantitativos, que possam ser aplicados com objetividade para geração de um número ao final. Atualmente, não se avalia a qualidade, mas apenas quantidade! Confere-se aos editores dos periódicos esse papel de fiéis da balança, mas com a demanda cada vez maior de produção de artigos os editores nacionais estão entrando em colapso, pois as revistas "rodam a engrenagem", praticamente, sem qualquer apoio financeiro, contando com a boa vontade de alguns poucos profissionais, que acreditam no que fazem, cenário que se agrava com a situação do país que, seja em âmbito nacional ou estadual, parece ver a ciência e tecnologia como primeira opção para corte de recursos.

A educação e a pesquisa brasileira necessitam deixar de lado essa característica de "ação entre amigos", profissionalizando-se e tendo apoio efetivo dos gestores, das empresas e dos distintos níveis de governo. Convidar os PPG para contarem a história, a evolução, os percalços e os sucessos dos últimos quatro anos, apontando a chegada de novos docentes, demandas dos alunos, aposentadoria de docentes, parcerias estabelecidas, propondo mecanismos de autoavaliação são possibilidades que devem ser pensadas e ensaiadas para que se possa dar mais um passo no processo de avaliação da pós-graduação brasileira. Afinal, o modelo tem sido um sucesso, já que em 1960 havia 38 cursos e, atualmente, há nada mais nada menos que 6.471 cursos! O desafio está posto para todos e cada um dos docentes. 


\title{
What is valuable or why? The weight of academic publication in the teaching area
}

\begin{abstract}
This article intends to analyze the academy productivity, in particular in the Education / Teaching area, which is mainly focused on understanding the actions of basic education with a public composed basically of teachers who are rethinking their professional practices. We seek to understand the state of the art of this subject from the analysis of the positions about the postgraduate courses evaluation process which takes account the quantitative of publications. We highlight some of the actions that begin with a rethinking of the evaluation processes undergone so far, especially in relation to the weight of the publication, and we suggest new forms of weighting that have in the barema a focal point of discussion. Within this field, one must go through the studies of the latest indicators that may extend to the analysis of the quality of the published articles. It is also necessary to establish approximations between the postgraduate programs in the scope and proposition to establish quality in the research which considers the time of reflection and experimentation in an appropriate way
\end{abstract}

KEYWORDS: Academic production. Teaching. Evaluation process. Postgraduate. 


\section{NOTAS}

${ }^{1}$ Albert Einstein em entrevista, apresentado na biografia: ISAACSON, W. Einstein, sua vida, seu universo. [S. I.]: Companhia das Letras, 2007.

${ }^{2}$ A recente Portaria no 389 da CAPES ampliou e revogou a Portaria no 17 ao incorporar o doutorado na modalidade profissional de pós-graduação stricto sensu, mas que ainda está em fase de regulamentação.

${ }^{3}$ A comunidade acadêmica de Ensino de Ciências e Matemática é anterior à criação da área na CAPES em 2000, acumulando discussão e produção acadêmica (reconhecida nacional e internacionalmente), além de atuar na formação de recursos humanos e na extensão.

\section{REFERÊNCIAS}

BARATA, R. C. B. Dez coisas que você deveria saber sobre o Qualis. Revista Brasileira de Pós-graduação, v. 13, n. 30, p.13-40, 2016. Disponível em: $<$ http://ojs.rbpg.capes.gov.br/index.php/rbpg/article/view/947/pdf $>$. Acesso em: 30 abr. 2017.

BIANCHETTI, L. Condições de trabalho e repercussões pessoais e profissionais dos envolvidos com a pós-graduação stricto sensu: balanço e perspectivas. Linhas Críticas, v. 17, n. 34, p. 439-460, 2011. Disponível em:<http://periodicos.unb.br/index.php/linhascriticas/article/view/6239/5113>. Acesso em: 30 abr. 2017.

BRANDÃO, M. A.; DECCACHE-MAIA, E.; BOMFIM, A. M. Os desafios da construção de um Mestrado Profissional: um panorama dos sete anos do Propec.

Polyphonía, v.24, n.22, p.93-111, 2013. Disponível

em:<https://www.revistas.ufg.br/sv/article/view/37941>. Acesso em: 30 abr. 2017.

BRASIL. Conselho Federal de Educação. Parecer no 977, de 3 de dezembro de 1965. Definição dos Cursos de Pós-graduação. 1965. Disponível em:<http://www.redalyc.org/articulo.oa?id=27503014>. Acesso em: 30 abr. 2017.

BRASIL. Ministério da Educação. Coordenação de Aperfeiçoamento de Pessoal de Nível Superior. Relatório de Avaliação 2010-2012. Trienal 2013. Ensino - Área 46. 2013. Disponível

em: $<$ https://docs.google.com/viewer?a=v\&pid=sites\&srcid=Y2FwZXMuZ292LmJy fHRyaWVuYWwtMjAxM3xneDozNGJiNzU0ODZiMGYOODMy>. Acesso em: $30 \mathrm{abr}$. 2017.

BRASIL. Requisitos para a Apresentação de Propostas de Cursos Novos (APCN). 
em:<http://capes.gov.br/images/documentos/Criterios apcn 2semestre/Crit\%C 3\%A9rios de APCN 2017 - Ensino.pdf>. Acesso em: 30 abr. 2017.

BRASIL. Documento de Área. Ensino. 2016b. Disponível em:<http://capes.gov.br/images/documentos/Documentos de area 2017/DOC UMENTO AREA ENSINO 24 MAIO.pdf>. Acesso em: 30 abr. 2017.

BRASIL. Regulamento para a Avaliação Quadrienal 2017 (2013-2016). Programas Acadêmicos e Profissionais. 2017. Disponível em:<http://capes.gov.br/images/stories/download/avaliacao/27032017Portaria-59-21-03-2017-Regulamento-da-Avaliacao-Quadrienal.pdf>. Acesso em: 30 abr. 2017.

CEVALLOS, I.; PASSOS, L. F. O mestrado profissional e a pesquisa do professor. Rev. Diálogo Educ., Curitiba, v. 12, n. 37, p. 803-822, set./dez. 2012. Disponível em:<www2.pucpr.br/reol/index.php/dialogo?dd99=pdf\&dd1=7204>. Acesso em: 30 abr. 2017.

CURY, C. R. J. Quadragésimo ano do parecer CFE n. 977/65. Rev. Bras. Educ., Rio de Janeiro, n. 30, p. 07-20, dez. 2005. Disponível em:<http://www.scielo.br/scielo.php?script=sci arttext\&pid=S141324782005000300002\&lng=en\&nrm=iso >. Acesso em: 30 abr. 2017.

FÁVERO, M. L. A. (Org.). A Universidade em questão. São Paulo: Cortez; Autores Associados, 1989.

GIL, A. C. Métodos e Técnicas de Pesquisa Social. São Paulo: Atlas, 2008.

KUHLMANN JR., M. Publicação em periódicos científicos: ética, qualidade e avaliação da pesquisa. Cadernos de Pesquisa, v. 44, n. 151, p. 16-32, 2014. Disponível em:<http://www.scielo.br/pdf/cp/v44n151/02.pdf>. Acesso em: 30 abr. 2017.

KUENZER, A. Z.; MORAES, M. C. M. Temas e tramas na pós-graduação em educação. Educação \& Sociedade, v. 26, n. 93, p. 1341-1362, 2005. Disponível em: $<$ http://www.scielo.br/scielo.php?script=sci arttext\&pid=S010173302005000400015\&lng=en\&nrm=iso>. Acesso em: 30 abr. 2017.

MACCARI, E. A. Contribuições à gestão dos programas de pós-graduação stricto sensu em administração no Brasil com base nos sistemas de avaliação norteamericano e brasileiro. Tese (Doutorado em Administração) - Universidade de São Paulo, Faculdade de Economia, Administração e Contabilidade, 2008.

Página | 64 
MARRARA, T. Internacionalização da Pós-Graduação: objetivos, formas e avaliação. Revista Brasileira de Pós-graduação, v. 4 n. 8, p. 245-262, 2007. Disponível em:<http://ojs.rbpg.capes.gov.br/index.php/rbpg/article/view/132/126>. Acesso em: 30 abr. 2017.

MOREIRA, M. A. O mestrado (profissional) em ensino. Revista Brasileira de Pósgraduação, v. 1, n. 1, p. 131-142, 2004. Disponível em:<http://ojs.rbpg.capes.gov.br/index.php/rbpg/article/view/26>. Acesso em: 30 abr. 2017.

MENDONÇA, A. W. Anísio Teixeira e a Universidade de Educação. Rio de Janeiro: Eduerj, 2002.

NUNES, C. Anísio Teixeira entre nós: a defesa da educação como direito de todos. Educação \& Sociedade, v.21, n.73, p. 9-40, 2000. Disponível em:<http://www.scielo.br/pdf/es/v21n73/4203.pdf>. Acesso em: 30 abr. 2017.

RÔÇAS, G. et al. O mestrado profissional em ensino de ciências do Instituto Federal de Educação, Ciência e Tecnologia do Rio de Janeiro: o desafio do ensino de pós-graduação na região da Baixada Fluminense do Rio de Janeiro. Ensino, Saúde e Ambiente, v. 4, n. 2, p. 2-16, 2011. Disponível em: $<$ http://ensinosaudeambiente.uff.br/index.php/ensinosaudeambiente/article Lview/91/90>. Acesso em: 30 abr. 2017.

SANTOS, A. L. F.; AZEVEDO, J. M. L. A pós-graduação no Brasil, a pesquisa em educação e os estudos sobre a política educacional: os contornos da constituição de um campo acadêmico. Revista Brasileira de Educação, v. 14 n. 42, p. 534-605, 2009. Disponível em:<http://www.scielo.br/pdf/rbedu/v14n42/v14n42a10.pdf>. Acesso em: 30 abr. 2017.

VELLOSO, J. Introdução. In: VELLOSO, J. (Org.). A pós-graduação no Brasil: formação e trabalho de mestres e doutores no país. Brasília: CAPES/UNESCO, 2002. p. 35-37.

VELTEROP, J. Seriam os periódicos 'predatórios' totalmente negativos, ou também um sinal de algo positivo? 2016. Disponível em:<http://blog.scielo.org/blog/2016/02/02/seriam-os-periodicos-predatoriostotalmente-negativos-ou-tambem-um-sinal-de-algo-positivo/\#.WSMrThPyt7M>. Acesso em: 30 abr. 2017.

VILELA, R. Q. B.; BATISTA, N. A. Mestrado Profissional em Ensino na Saúde no Brasil: avanços e desafios a partir de políticas indutoras. Revista Brasileira de Pós-graduação, v. 12, n. 28, p. 307-331, 2015. Disponível 
em:<http://ojs.rbpg.capes.gov.br/index.php/rbpg/article/view/823/pdf $>$. Acesso em: 30 abr. 2017.

VILLANI, A. Mestrado profissional em ensino de ciência e matemática: uma interpretação. Revista Ibero-americana de Estudos em Educação, v. 11, n. esp. 1, p. 418-433, 2016. Disponível

em: $<$ http://seer.fclar.unesp.br/iberoamericana/article/view/8563/5744>. Acesso em: 30 abr. 2017.

YAMAMOTO, O. H. Publish or perish: o papel dos periódicos científicos. Estudos de Psicologia, v. 5, n. 1, p. 3-9, jun. 2000. Disponível em:<http://www.scielo.br/scielo.php?script=sci arttext\&pid=S1413294X2000000100001\&lng=en\&nrm=iso>. Acesso em: 30 abr. 2017.

Recebido: 30 maio 2017

Aprovado: 05 jun. 2017

DOI: http://dx.doi.org/10.3895/etr.v1n1.5949.

Como citar:

RÔÇAS, G.; ANJOS, M. B.; PEREIRA, M. V. Quanto vale ou é por quilo? O peso da publicação acadêmica na área de ensino. Ens. Tecnol. R., Londrina, v. 1, n. 1, p. 46-66, jan./jun. 2017. Disponível em:

$<$ https://periodicos.utfpr.edu.br/rbqv/article/view/5949>. Acesso em: XXX.

Correspondência:

Giselle Rôças

Rua Lucio Tavares, 1045, Centro, Nilopolis, Rio de Janeiro, Brasil.

Direito autoral:

Este artigo está licenciado sob os termos da Licença Creative Commons-Atribuição 4.0 Internacional.

(c) (1) 